\title{
Exploring Global Health Disparities: Afro-Caribbeans' Perceptions of the Prevalence of Type II Diabetes in Their Communities
}

\author{
${ }^{1}$ Cecilia Deterville, ${ }^{1}$ Shewanee Howard-Baptiste and ${ }^{1}$ Valeria Freysinger
}

${ }^{1}$ Miami University, Oxford, OH, USA

DOI: $10.47611 /$ jsr.v9i1.1026

\section{$\underline{\text { ABSTRACT }}$}

Non-Communicable diseases (NCDs) as defined by the World Health Organization (WHO) (2008a) are cancers, chronic respiratory diseases, cardiovascular diseases and diabetes. NCDs diseases are chronic and non-infectious. Combined, these four killers cause an estimated 35 billion deaths annually (WHO, 2008b). According to WHO (2005, 2008b), $60 \%$ of the 35 billion represents all deaths globally. Moreover, the WHO (2005, 2008b) reports that with all the deaths that occur in low and middle-income countries, $80 \%$ of those deaths will be a result of NCDs. According to Magnusson (2010), NCDs present a huge threat to public health. The prevalence of NCDs is simply not an individual or a national problem. It is one that deserves global attention, because it affects all people regardless of age, race or geographic location. Its prevalence arises, at least in part, from global economic practices and the global distribution of wealth (Beaglehole \& Yach, 2003). NCDs account for most deaths in individuals 15-59 years of age in all regions of the world except South Asia and Sub-Saharan Africa (Lopez, Mathers, Ezzati, Jamison, \& Murray, 2006). NCDs are highly prevalent in low and middle-income countries, where historically people were once more affected by infectious or communicable diseases.

There are a number of disease conditions that are highly prevalent in persons of African descent, and diabetes mellitus (type II diabetes) is one of them (Solomon, 2003; Ali et al, 2015). However, it is not only the prevalence of NCDs that is of concern, but also the increasing disparity between developing and developed nations of this rapidly growing disease (WHO, 2008b; Wild et al., 2004).

Developing countries like the countries of Latin America and the Caribbean have one of the highest burdens of diabetes globally (Yisahak, Beagley, Hambleton \& Narayan, 2014). For example, diabetes mortality in CARICOM countries is one of the leading causes of death, along with chronic respiratory diseases, cancers, and cardiovascular diseases (PAHO, 2007). Research by Guariguata et al. (2014) demonstrates that the global estimates of diabetes are much higher than initially projected by many professionals of this work, including the renowned World Health Organization (WHO). In addition, researchers have also pointed that the top ten countries with the highest per capita health expenditure on diabetes are all from developed countries (Zhang et al., 2010).

King et al. (1998) makes a clear note of the stark difference in the predicted prevalence of diabetes in developing countries as opposed to developed countries. That is, the proportional increase in diabetes will be greater in developing countries, where the increase in prevalence will be $48 \%$, in contrast to just a $27 \%$ increase in developed 
countries. In fact, many public health officials predict approximately $75 \%$ of all cases of type II diabetes worldwide will be in developing countries by the year 2025 .

\section{Type II diabetes as a growing burden on the Caribbean community}

Chronic conditions such as heart disease, stroke, diabetes and cancers are unfortunately causing disease and disability for people regardless of age, race, gender or socioeconomic status. Yet, those same characteristics and social determinants of health can increase the prevalence of these conditions in many people throughout the world. Particularly, our neighbors in the Caribbean are experiencing complications and death due to chronic conditions and comorbidities that leave many communities puzzled about how to address health concerns like high blood, high cholesterol and diabetes. Historically, many Caribbean islands did not experience the impact of NCDs until the most recent decades. Researchers must look broadly and deeply to assess the changing factors specifically in AfroCaribbean communities that speak to the increased incidence and prevalence rates of type II diabetes. It is necessary to explore the ways in which geography, ethnicity, socioeconomic status, age, access to food, and opportunities for adequate healthcare.

Diabetes is a major risk factor for cardiovascular disease, kidney disease and blindness (Bloom et al., 2011). Historically, individuals living throughout the Caribbean had significant lower rates of being overweight, being obese, having type II diabetes and other chronic conditions (Figueroa, 2001). This is not to suggest Caribbean people have not faced non-communicable diseases in the past; rather, the prevalence rates are higher now than they have been decades ago. For example, the top leading causes of death in Jamaica in 1945 were tuberculosis, heart disease, nephritis, syphilis, pneumonia and influenza (Wilks et al., 1998). Ferguson et al. (2011) then illustrated that in 2004, the leading causes of death in Jamaica were cerebrovascular disease, diabetes mellitus, ischemic heart disease, hypertensive diseases and other heart diseases.

A review of the literature reveals some insight into the topic of health disparities and type II diabetes among people of African descent in the Caribbean. Boyne's (2008) extensive review of the literature revealed that the Caribbean is undergoing "a rapid epidemiological and nutritional transition" (p. 95), where communicable diseases accounted for about $5 \%-10 \%$ of all mortality rates and chronic, non-communicable diseases have assumed prominence. In contrast, half a century ago, the most common causes of mortality in the Caribbean at the time were infections.

However, the literature is very dated and limiting in going beyond the surface to further the discourse of lifestyle factors that is commonly presented as contributing factors to the increasingly higher prevalence of type II diabetes among people of African descent presently living in the Caribbean. Research shows that the rate of type II diabetes is increasing at an alarming rate and it is especially more pronounced in developing countries like the Caribbean, where a majority of the deaths from non-communicable diseases, like type II diabetes will occur.

The risk factors associated with NCDs are well-known and extensively researched. These universal risk factors include lifestyle factors such as, tobacco use, a poor diet, physical inactivity and the harmful consumption of alcohol (WHO, 2008b, 2011). However, this paper aims to go beyond these lifestyle risk factors to assess broadly and deeply those social determinants of health that are specific to Afro-Caribbean families that affect their current state of health and the increased incidence and prevalence rate of NCDs, specifically type II diabetes. 
Developing low- and middle-income countries of the Caribbean are extremely diverse. The people who make up this diversity are multi-lingual, multi-cultural and multi-racial (Trouillot, 1992). Islanders, as sometimes they are referenced, could be from the same country but speak multiple dialects and have varying lived experiences. Political, economic, educational, and health are also diversified in the Caribbean and within a country from region to region. For this reason, this paper examines specifically the increased prevalence of type II diabetes among English speaking peoples of Afro-Caribbean descent living on the Caribbean islands of Dominica, St. Lucia, Jamaica and Barbados.

Individuals from these four countries were identified because they share particular characteristics that would make it easier to explore NCDs such as diabetes in their communities. For instance, all four islands are former British colonies, whose large African population is as a result of the slave trade. The population of people who are identified as being of African descent in Dominica, St. Lucia, Jamaica and Barbados are 86.6\%, 85.3\%, 92.1\% and 92.4\% respectively (CIA Factbook, 2018). These four countries are relatively small countries, with Jamaica being the largest in terms of population size and land mass. These four countries are relatively in close proximity to each other geographically with Jamaica being the farthest away. In addition, these four Caribbean countries have similar developing economies, which rely heavily on tourism and agriculture as main sources of income (Punnett, Dicke-Forde \& Robinson, 2006).

\section{Perspectives on Health in the Caribbean}

There has been a tremendous change in health conditions over the last few decades in the Caribbean. Although people are living much longer, they are doing so with NCDs, such as cancers, diabetes, and cardiovascular diseases. Although these countries proportionally experience the majority of deaths from NCDs, it does not mean that they no longer experience communicable (infectious) diseases and their concomitant mortality. They simply struggle with both. However, evidence points to a global epidemiological shift, where the majority of deaths from NCDs are now largely due to chronic diseases and no longer just infectious ones (Miranda, Kinra, Casas, Smith \& Ebrahim, 2008). For instance, Ali and colleagues (2015) compiled mortality data for males and females ages 0 - 85 years for cardiovascular diseases, diabetes, chronic respiratory diseases and cancers in countries with suitable data since 1980 2012. In Trinidad \& Tobago, they found that diabetes mortality rates continued to rise with each passing year.

Gulliford's (1994) review provides a glimpse of health conditions and health care services in the Englishspeaking Caribbean from colonial times to present day. Health conditions in colonial times were riddled with high infant mortality rates, malnutrition, and infectious diseases such as malaria. Beginning in the 1960s, at a time, when these countries began to gain independence from colonial rule, health conditions saw a decrease in communicable diseases and an increase in non-communicable diseases. According to Gulliford (1994), Health ministers have indicated both communicable and non-communicable diseases of major concern, despite the fact that expenditure on health care is a lower proportion of the Gross Domestic Product (GDP) compared to more developed countries.

\section{Health Consequences of Type II diabetes}

Diabetes is a major risk factor for other causes of death and has a high attributable burden of disability. Barcelo, Aedo, Rajpathak \& Robles (2003) did their best to quantify the direct and indirect costs of diabetes in the English- 
speaking Caribbean. They determined that access to healthcare in the Caribbean is limited; as a result, the direct and indirect costs may exceed direct healthcare costs. At any rate, they estimated 7,776 deaths for every 1 million population, 15,064 people permanently disabled from diabetes-related complications, and hundreds more affected with diabetes-related complications. Furthermore, they estimate that hundreds of dollars would be spent on the cost of medications, and the costs related to caring for diabetes-related complications.

Many researchers have documented the high rates of diabetes-related complications that cause physical, financial and psychological burden in the Afro-Caribbean population. Cawich et al. (2014) documented high rates of hospitalizations for foot infections and diabetes-related amputations. It goes without saying that disabilities that come with unmanaged and uncontrolled type II diabetes cause a significant decrease in quality of life. In a qualitative study using one on one interviews with type II diabetics people of Afro-Caribbean people, a few of the participants encouraged health professionals to be more open about the risks and complications with having type II diabetes. Those participants felt that is was important for them to understand these risks and be better informed and educated, so they can have a better understanding of their disease process, which they can better explain to others (Brown, Avis \& Hubbard, 2007).

In a second qualitative study that explored perceptions of type II diabetes among Afro-Caribbean, discussions on quality of life were of major significance (Noakes, 2010). Some of the participants were worried about living alone as it would be dangerous to do so if there was a sudden complication, such as a hypoglycemic episode. Those participants feared the worse if there wasn't someone else in the home to support and care for them if there was an emergency.

In sum, the costs of diabetes - personal, economic, and societal - are significant. Individuals living with this debilitating disease are worried and fearful. They require more from the healthcare system and they want to live productive lives for themselves and their families. Reducing the incidence and prevalence of, as well as rates of mortality and morbidity associated with type II diabetes on a global scale, would be beneficial for all.

\section{The Impact of Social Determinants of Health on Caribbean Life}

According to the Centers for Disease Control and Prevention (CDC), if not addressed, social determinants of health such as poverty, unsafe neighborhoods, poor housing, inadequate education, and poverty can negatively impact the health of individuals and communities in the United States and abroad. Samuels and Fraser (2010) contend that public health educators must look beyond individual lifestyle and instead focus on social determinants of health, which include urbanization, globalization, education, and aging. They also contend that these social determinants of health provide the contexts for unhealthy eating, physical inactivity, tobacco use, and alcohol abuse.

Although there are few studies that examine health in the Latin American and the Caribbean region (LAC), one study provides a very important and dynamic view on health disparities in the LAC region among people of African descent and those of indigenous cultures. In this review of literature, Giuffrida (2010) notes that the health disparities that are present and that affect peoples of the Latin America and the Caribbean are "the result of complex dynamics between social exclusion, poverty, and adverse environmental factors, as well as cultural and behavioral factors" (p. 116). The interplay among these factors has caused great health inequalities and as a result, efforts to reduce health inequalities in the LAC region have to take these factors into account (Giuffrida, 2010). 
In fact, Giuffrida (2010) advocates for several policies to reduce health disparities in the region. First, Giuffrida (2010) believes that there needs to be more recognition that there is health disparity that exists among those of indigenous and African descendant populations. Furthermore, it is imperative that there is effective provision of health care services to indigenous and Afro-descendant groups that addresses geographical and cultural barriers to receiving care. Additionally, addressing issues of poverty, employment and education will reduce disparities in health among indigenous and groups and people of African descent. Giuffrida (2010) notes that there has been systematic denial of certain employment, job advancement and education for these groups, which have forced them to live in inter-generational poverty, thus experiencing poor health. Lastly, Giuffrida (2010) calls for affirmative action and positive discrimination policies that would promote health equity in the LAC region. Similar research highlights the health inequalities that exist among people of African descent in the United States.

\section{Increase of Large Industries \& Poor Diets}

In many Latin American countries, as already stated, a diet high in fat, sugar and processed foods increases one's chances of developing a number of health complications, including type II diabetes. Still many public health educators continue to use the language lifestyle risk factors only and believe that the prevention of NCDs begin by reversing their shared risk factors, that is, changing individuals' behaviors. However, data shows that in many of the developing countries of Latin America, giant supermarkets are replacing traditional food outlets, known for their rich variety of local fruits and vegetables, to more processed food items that are high in sugar, salt, and fat leaving local populations with poor food choices and diets (Ley, Hamdy, Mohan \& Hu, 2014; Reardon Timmer, \& Berdegue, 2003).

Pekusa (2002) brings attention to nutrition as being a necessary framework in the prevention of NCDs. Changes in nutrition at the national level would discourage unhealthy eating, thus promoting healthy eating aiding in the prevention of NCDs. However, Pekusa (2002) argues that this change should come from a collaborative approach - that is, an approach that involves health services, schools, mass communication, media, public organizations, restaurants, supermarkets, the food industry, legislation and policy, and research. Effective collaboration from these sectors and areas can remove barriers to accessing healthy foods and healthy diets.

\section{Healthcare System \& Emigration}

In a presentation entitled, Health Workforce Migration and the Caribbean Region, (2006), a representative of the Office of the Caribbean Program Coordination, contended that weak health care systems have evolved in countries of the Caribbean region, a region that is constituted by low and middle-income countries. Barclay (2006) points to several reasons for this, stating that there has been active and favorable recruitment of skilled health professionals from the Caribbean to the United States. The emigration of nurses, physicians, and health researchers from the Caribbean to the United States and elsewhere has led to a reduction in skilled health care labor from those regions. Hence, these countries are experiencing severe limitations in their commitment and capacity to provide equitable, quality health care services to their citizens. In addition, Barclay (2006) suggests that the emigration of skilled workers from the Caribbean has slowed progress in economic and social sectors in the region. For example, emigration has led to a weak infrastructure and leadership to collect and manage data and to finance social services for the 
region. Hospendales et al., (2012) state that "a lack of trained human resources to prevent and control NCDs is a major challenge" (p. 80) for countries of the LAC region.

This lack of quality care was noticeable at the only public hospital in Barbados by Taylor et al., (2014). The lack of strategies, quality and educated personnel to effectively manage diabetic foot disease was studied in Barbados as a major health problem, where the feet of diabetic patients were infrequently examined. Moreover, these diabetic patients experienced medication errors at the hands of health professionals.

\section{Decreases in Economic Development}

Another perspective on the increasing global prevalence of NCDs points to global rule and power imbalances that put a strain on the ability of countries to properly respond to health problems (Beaglehole \& Yach, 2003). Beaglehole and Yach (2003) argue that the power, prestige and resources of more developed countries, for example, U.S. and European Union agricultural subsidies, make it very difficult for producers of fresh produce in developing countries to compete. This results in a reduction in the national average income of developing countries. For example, St. Lucia's once solid banana industry has been devastated by strong competition; thereby, weakening the country's economy (CIA Factbook, 2018). In addition, the increasing awareness and availability of salty, sugary foods, tobacco products, and alcohol due to large multinational corporate marketing campaigns that now permeate developing countries make it difficult for those countries to promote healthy behaviors (Beaglehole \& Yach, 2003).

\section{Role of Urbanization and Globalization}

Perel, Casas, Ortiz and Miranda (2006) also point to two major factors that have been driving the growth of NCDs in Latin America and the Caribbean: urbanization and globalization. They argue that the urbanization and globalization has contributed to an increase in unhealthy behaviors by worsening dietary patterns and lowering physical activity levels: people rely more on convenience foods and often walk less, relying on personal and public transportation as their means to get around.

\section{Poverty}

A unique perspective on social determinants of health in the Caribbean region is discussed by the Pan American Health Organization (PAHO), the oldest, international public health agency working to improve health and living standards of the people of the Americas. PAHO discuss specifically those social determinants of health that are unique to each country. In St. Lucia, PAHO (2012) explains that the social determinants of health are poverty where 2005 assessments showed that $18.7 \%$ of household and $25.1 \%$ of individuals lived below the poverty level; literacy - where in 2012, literacy among young females aged 15-24 was 99.3\%; unemployment - where the unemployment rate was $24.4 \%$ and youth unemployment had increased to $41.8 \%$ in 2014 ., and the access to clean drinking water, sanitation and natural disasters (hurricanes and tropical storms). In Jamaica, a qualitative study explored perceptions of type II diabetes among Afro-Caribbean. One of the participants highlighted the lack of healthcare in Jamaica for those living with type II diabetes, which caused family members to die prematurely, because they could not afford the insulin and blood glucose monitoring system (Noakes, 2010).

Yisahak et al. (2014) compiled prevalence rates of diabetes in North America and the Caribbean to produce estimated numbers of people living with diabetes and projections for 2035 . They believe that certain social determi- 
nants of health such as social disadvantage and low socioeconomic status is contributing to this increased risk. They also came to the conclusion that the risk of diabetes and its complications is higher among people of African descent in several Caribbean countries, such as St. Lucia, Dominica, Jamaica \& Barbados.

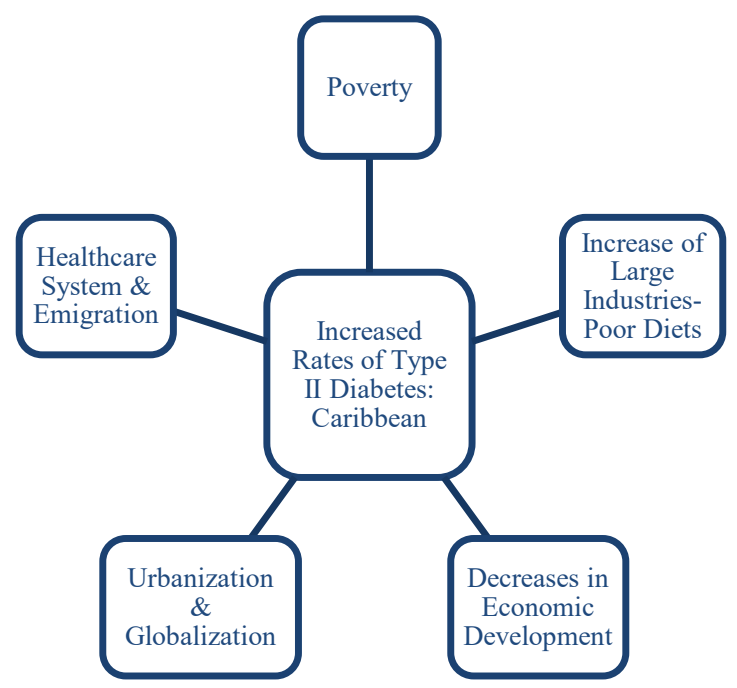

Figure 1: Factors Leading to Increased Rates of Diabetes in the Caribbean

The Impact \& Rates of Type II Diabetes in the Caribbean: Dominica, St. Lucia, Barbados \& Jamaica

\section{Dominica}

In 2010, diabetes mellitus ranked as the second leading cause of death in the country, peaking as the leading cause in 2011. The 2007 STEPS survey revealed that $57.2 \%$ of respondents had a family history of diabetes, and more than one-quarter (28.2\%) had fasting blood glucose levels of over $110 \mathrm{mg} / \mathrm{dL}$, was currently on medication for diabetes, or had been previously diagnosed with the disease. Lower-limb amputations (greater among males than among females) and diabetic retinopathy leading to blindness are the main complications from diabetes in Dominica (Pan American Health Organization, 2007).

A study by Butler and colleagues (Butler, Tull, Chambers, \& Taylor, 2002) focused on glucose intolerance (a precursor to developing Type II diabetes) among people of African descent on the Caribbean island of Dominica. Specifically, Butler et al. (2002) examined the relationship between internalized racism as a psychological stressor and glucose intolerance in a sample of 244 women, aged 18-55 years. Although experiences of overt racism experiences are not part of the daily lives of Black people in mostly Black Caribbean countries like Dominica, the researchers argued that racist propaganda, which began with the slave trade in the $18^{\text {th }}$ century, has become internalized by many Western Hemisphere Blacks. Hence, the researchers measured both internalized racism and hostility towards Dominicans. The results of the research indicated that those with high internalized racism had a significantly larger waist circumference compared to those who had measured lower rates of internalized racism. Moreover, 
internalized racism remained independently associated with elevated fasting glucose, compared to those women with low levels of internalized racism. That is, racism increased the chance that these Dominican women would develop type II diabetes.

\section{Saint Lucia}

St. Lucia is another English-speaking country in the Caribbean where little research has demonstrated the rates of type II diabetes among its peoples. The ones who focus specifically in the Caribbean are rather dated. Diabetes mellitus is one of the leading causes of death on the island. According to PAHO (2007), there were 133 deaths per 100,000 in 2004 when the population was about 150,000. According to the Pan American Health Organization (2012), 71\% of all deaths from defined causes in St. Lucia were as a result of non-communicable diseases. Diabetes Mellitus was the 4th leading cause of death in Saint Lucia from 2006 - 2008. An analysis of hospital data for the period 2007- 2009 showed that diabetes and hypertension accounted for $27 \%$ of all admissions. Of those admissions, hypertension accounted for $50 \%$, diabetes for $27 \%$ and co-morbid diabetes and hypertension for $23 \%$.

\section{Barbados}

In 2010, researchers collaborated with each other to quantify for the first time, the national rates of lower extremity amputations in a Caribbean population, which is known to have high rates of diabetes. There were 261 hospital admissions for diabetes and one quarter of all adult Barbadians have a chronic non-communicable disease (Ministry of Health (Barbados), Chief Medical Officer's Report 2010 - 2012). Diabetic lower-extremity amputation rates in Barbados are among the highest in the world. Over a 12-month period, the incidence of diabetes-related lower-extremity amputation rates were 936 per 100,000 including 557 for minor amputations and 379 major amputations (Hennis, Fraser, Jonnalagadda, Fuller, \& Chaturvedi, 2004). Another noteworthy research on the prevalence of diabetes mellitus on the island of Barbados also comes from Taylor Jr et al. (2014). They evaluated the burden and quality of adult inpatient diabetes care in Barbados. Their research found that out of the two hundred and sixty beds that were audited at the only public hospital in the country, one hundred and eleven of those beds were occupied by patients with diabetes mellitus. One hundred and ten of those patients were of Afro descent. In fact, their research found that the prevalence of inpatient diabetes mellitus was the highest in the English speaking literature. Boyne (2008) concluded the same in an extensive PubMed literature search for the period 1951 to 2008 on diabetes research in English-speaking Caribbean countries. He found that Barbados was noted to have the highest prevalence of diabetes in Latin America and the Caribbean in the 1970s.

\section{Jamaica}

From 2010 to 2014, the five leading causes of death in Jamaica were due to non-communicable diseases (NCDs) and injuries. Researchers recruited a random population sample from Spanish town, Jamaica to characterize the prevalence of diabetes in the Jamaican population. In 1999, the results were published and it was concluded that the prevalence of diabetes in Jamaica exceeded that observed among European-origin populations (Wilks et al, 1998). Many other researchers have documented that the prevalence of diabetes in Jamaica has increased and continue to increase. One study that documented this increase is by Bryan et al. (2012). They assessed risk factors for type II diabetes 
among women in rural Jamaica and $40 \%$ of the participants interviewed indicated that they had immediate family members who had diabetes. Most importantly, $70 \%$ of these participants interviewed did not have health insurance.

Mitchell-Fearon et al. (2015) also researched Diabetes to be highly prevalent in Jamaica. They reported more than one in four $(26.2 \%)$ older adults, with females reporting a significantly higher prevalence than males $(32.3 \%$ versus $19.6 \%)$. In another study, based on a sample of 3,500 individuals aged 15 and older participating in the Jamaica Health and Lifestyle Survey III, which was carried out 2016-2017, and aims to account for public health issues impacting Jamaicans throughout the country had preliminary results that found that $12 \%$ of individuals over the age of 15 had diabetes and "diabetes was more prevalent among Jamaicans 75 years and older (42\%). Additionally, $12 \%$ of Jamaicans had pre-diabetes with a higher prevalence in women (13.3\%) than men (10.7\%)." "Among person 15-74 years, the prevalence of diabetes was approximately 10\%, and this compares to $7.8 \%$ among the same age group in the Jamaica Health and Lifestyle II done in 2007/08” (Ministry of Health (Jamaica), 2018, p. 2).

\section{Study Data \& Methods}

Due to the fact that little research has been conducted on the realities of type II diabetes in the Caribbean region (Boyne, 2008), this qualitative research is interested in capturing the presence of type II diabetes in the Caribbean among people of African descent. This research will also assess how type II diabetes affects the family unit. Lastly, this study will assess the potential causes for the increasing prevalence of type II diabetes in these designated regions.

The goal is to develop to an understanding of why these disparities exist from the perspective of members of those communities - that is, to understand how individuals most affected make sense of the prevalence of Type II diabetes in their family and their communities. A critical exploration of the contexts and experience of diabetes is needed in this region. The purpose of this proposed study was to examine more of a critical and holistic approach to the prevalence of type II diabetes in people of African descent in developing countries of the Caribbean based on their lived experiences. It was important to gain more of an understanding of this disease and to pinpoint any areas or causes for its disproportionate effects on the Afro-Caribbean family. Furthermore, this research highlights the prevalence of type II diabetes in the target population in regards to prevention, diagnosis, treatment, and mortality rates.

Six participants were interviewed in 2012: two were male and 4 were female. These participants ranged in age from 22 to 24 years and were able to give consents to be interviewed. In order to protect their identities, the participants chose pseudonyms. All participants were of African descent and were born and raised in the Caribbean. Specifically, Ryan and Maria are citizens of St. Lucia; Imani, a citizen of Dominica; Mac and Stephanie are citizens of Jamaica and lastly, Nola is a citizen of Barbados. Three of the participants had their permanent addresses in the West Indies while the others were currently residing in the United States. All of the participants were college educated. At the time of the interviews Maria, Nola and Imani were currently enrolled in graduate school programs in the United States. The other three participants, Ryan, Mac and Ryan were fully employed: Mac and Imani were fully employed in the United States and Ryan was fully employed in St. Lucia.

Through the use of convenience, purposive, and snowball sampling (Mason, 2002), the study participants were recruited from the researcher's personal and professional network. In other words, the participants were easily 
accessible to the researcher. The recruitment of the study participants initially began with snowball sampling, where one of the participants was known to the researcher. This participant then recommended another individual who had the knowledge and experience to speak on the topic of discussion, and from there, the participant list grew surprisingly well. This may speak to the growing prevalence of type II diabetes in Afro-Caribbean communities, where someone knows someone living with type II diabetes. The use of this technique was unexpectedly promising in recruiting the participants in an efficient manner. It is important to note that although the study participants were known to the researcher, they are not relatives of the researcher. Each participant was able to provide information that is meaningful and relevant to the study. Regarding eligibility, the participants interviewed did not necessarily need to have a diagnosis of type II diabetes to be eligible for participation in this study. Imani was the only participant who had a diagnosis of type II diabetes. She also spoke about her nuclear family, who also live with type II diabetes. The other five participants have close family members who dealt with this chronic disease and had first accounts of how the disease has impacted their family and communities. They view each day how type II diabetes affects their home and they can see its effects on their loved ones, making them excellent people who can speak to how type II diabetes has changed the family landscape. Stephanie spoke about her grandmother who lived many years with type II diabetes. Mac spoke about his uncle who had being diagnosed with type II diabetes. Ryan spoke about a close friend who lives with type II diabetes. Maria spoke about her father, uncles and aunt who all live with type II diabetes. Lastly, Nola spoke about her grandparents who live with type II diabetes.

Research Questions asked pertained to causes for the increase in type II diabetes, feeling towards type II diabetes in the participant's community, how the diagnosis of type II diabetes has affected the family unit and action steps to reduce type II diabetes. In a response to the question- How do Afro-Caribbeans make sense of the increasing prevalence of type II diabetes? - Six themes were generated from the interview data. Several subthemes comprised each these larger themes.

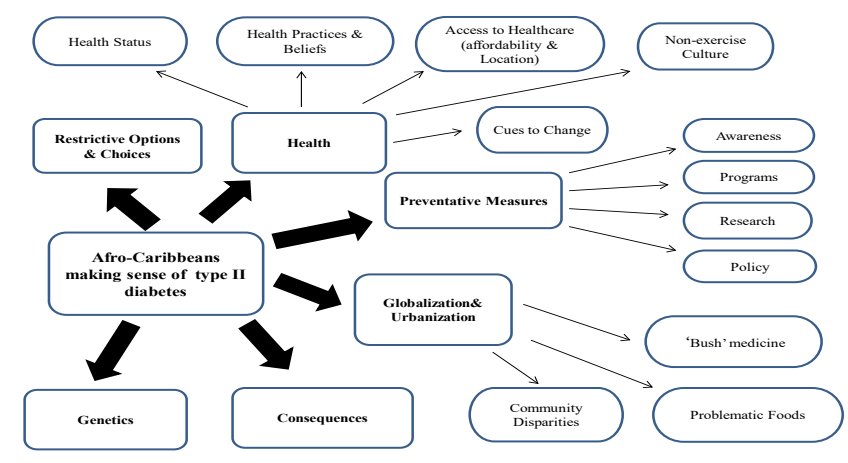

Figure 2: How Afro-Caribbean Population Make Sense of Type II Diabetes

These themes capture study participants': (1) feelings about the disease, (2) beliefs about how the disease had come to be so entrenched in their communities, and (3) perceptions of measures that have been put in place to control the rise of type II diabetes. The six themes and their sub themes are described below. Quotes from the participants illustrate each theme and subtheme. 


\section{Discussion}

\section{Globalization and Urbanization}

This theme refers to study participants' perceptions that an increase in urban life and globalization has made its way into the Caribbean, gradually changing the natural landscape of West Indian life. Globalization is described as the integration of economic, political, and cultural systems across countries and nations (Perel et al., 2006). Although there are both positive and negative aspects of globalization, the participants who contributed to this research, for the most part, highlighted the negative aspects of globalizations that they perceive as being detrimental to the health of Afro-Caribbean people. As noted by Stephanie (born and raised in Jamaica): So back in the day, the market is critical to the town and is very central and it sells a lot of vegetables and fruits ... But with the increase in industrialization back at home, the wholesale and the retailers coming in, a lot of people are moving from the fresh goods in the market and going to the wholesale and supermarkets to purchase processed food. There's a high amount of individuals who are purchasing cars. So, back in the day, we used to walk to certain places and it would provide at least some form of exercise for the day, now you just take the taxi and drive to work or wherever you're going, that has contributed to a lack of exercise and may have played a role in the increase of diabetes in Jamaica.

Similarly, Mac who is from Jamaica said: Kingston, it's so urbanized, because people don't have anywhere to plant their own foods ...everything that you want, you have to go to the grocery store and get it; whereas, in the countryside people have all those things on their property.

And Nola from Barbados noted: “...especially in the city people don't have that much space to play or they can't play after dark, because you know there are too many cars around or stuff like that."

The detrimental aspects of globalization and urbanization include the increasing prevalence and convenience of unhealthy foods in Caribbean nations, the poor health of West Indians, the tensions arising from differences between western medicine and local (bush) medicine, and lastly, immigrant culture in the U.S. as a response to West Indians immigrating to the U.S. The sub-themes under this larger theme include: bush medicine, problematic foods, and community disparities.

\section{Bush medicine}

Maria speaks to the role of bush medicine in disease management in St. Lucia: He thought the alternative, which was bush medicine, is better than the pills...especially older folk who largely believe that western medicine is not as effective at treating conditions, like, as bush or the traditional medicine can.

\section{Problematic foods.}

Maria \& Ryan (St. Lucia) and Stephanie (Jamaica) all speak about the role of nutrition in the health of the people in their communities: I think that our diet on the island contributes a lot to the diabetes rate on the island, because you'll find a fast food joint on every corner.... And my goodness, soft drink is being consumed at a high level...To start with, we have been invaded by Chinese, and they prepare rice, fried rice they call it, but the chicken is not done in a healthy way... there's KFC, there's Church's chicken, and these places sell the same thing: fries, fried chicken, burgers, and the likes. (Ryan, St. Lucia) 
I think it's the type of foods that you eat back at home . . . white rice and vegetables is just a side thing. You don't eat vegetables as a whole meal as some people do here. Fruits and vegetables are just a side and you always have a drink. There's no water, you always have your juice, and it's like every day you eat your rice and your meat in portions that are in huge portions .... fruits and vegetables were not emphasized as something, not necessarily as something, as part of the meal per se. (Stephanie, Jamaica)

At the same time, others perceived traditional foods as also problematic: Well, on the plate would be like a mountain peak of what we call ground provisions, which would include yams, dasheens, breadfruit, green bananas; and on this plate would be none to very little vegetables, and meat whether it's in the form of red meat or chicken or fish or any other type of meat would be in large proportions. (Maria, St. Lucia)

\section{Community disparities}

Imani (Dominica) describes her predominantly, Afro-Caribbean neighborhood in Brooklyn to that of a White neighborhood in which she works, also in Brooklyn, New York: I work in Park Slope, Brooklyn, which is a predominantly white area of Brooklyn, and you walk into their stores and there's a 360- a complete 360, very different'...The snacks that you would find like the Lays, the kettle chips, the cookies is not found. When you go to Park Slope, everything is organic, it's a vegetable chip, it's a vegetable, it's a fruit... it's something. If they have these other chips, it's tucked away in a section, a little box that would have a pack of Lay's or whatever. But, for the most part, everything is just so healthy, organic, locally grown. It's just a world difference...A major disparity...

\section{Restrictive Options and Choices}

To many of the study participants, type II diabetes was synonymous with restrictions and limitations. As indicated by the interviews, type II diabetes was seen as limiting in the sense that it restricts food choices and activity levels. "For example, with her diet; she [girlfriend's mom] basically has a list of things that the doctor says eat and cannot eat and she wouldn't, almost, not go out of that list." (Ryan, St. Lucia). Mac also speaks openly about his uncle's restrictive food options: He's [uncle] very careful to what he eats at home, he doesn't drink as much as he used to...it's only brown rice and I believe now there's no rice; I believe its bulgur.... Low sodium; not a lot of red meat; he cuts out the sugary stuff. (Mac, Jamaica)

Stephanie (Jamaica) spoke about the losses and limitations her grandmother experienced because of type II diabetes: "She stays in a lot more. I think it's because of the poor eyesight. She lost her job a year ago. She wasn't able to really help her patients as best as she could."

\section{Health}

Perhaps more than anything else study participants associated type II diabetes with health, specifically Caribbeans' health status, health practices and beliefs, access to healthcare (location and affordability), non-exercise culture, and the need for cues to change health behaviors. 


\section{Health status}

It [type II diabetes] is very high in Jamaica. I mean it is very, very high in Jamaica with a lot of people. It is the lack of primary health care or adequate healthcare, especially in rural areas, a lot of people might have it and don't even know that they have it... and it's being one of the number one killers back at home. (Stephanie, Jamaica)

"I mean, Barbados has an extremely high prevalence of diabetes and it's one of the major health issues" (Nola, Barbados).

"There was some awareness going on island-wide, because what the health officials in our country find out was that we have the highest rate of diabetes, world-wide per capita..." (Ryan, St. Lucia)

\section{Health practices and beliefs}

Stephanie (Jamaica) discussed the health practices her grandmother now engages in to help her better manage this disease: She changed her diet drastically after realizing that she had type II diabetes... she started eating mostly fruits and vegetables; less starchy foods, less salt and less sugary drinks. Every now and again, she'll have juice, but otherwise just water, and yes, just making sure things are a little bit more balanced in terms of fruits and vegetables. Stephanie (Jamaica) then discusses the differences between men and women in the home when seeking care:

...they have this thing where you would almost never see a man at the hospital, unless it's really severe. So, primary healthcare for men is deemed as something that women do; and unless you are really, really sick, you're (i.e. men) not going to get your regular check-up. So, even though they have it (diabetes), I don't even think they would know per se... (Stephanie, Jamaica)

Nola (Barbados) provides an important lesson in how people form Barbados view diabetes:

I mean, Barbados has an extremely high prevalence of diabetes and it's one of the major health issues. I think a lot of people don't take it seriously, because it's entirely to the point now that you can live a full life while being a diabetic. They don't take it seriously and don't realize how dangerous it could be...They don't take things like adjusting their diet or things like getting more exercise seriously stuff like that.

\section{Access to healthcare (location and affordability)}

It is the lack of primary health care or adequate healthcare, especially in rural areas, a lot of people might have it and don't even know that they have it. So, it's very high and it's being one of the number one killers back at home. (Stephanie, Jamaica)

Stephanie (Jamaica) then explains the differences in cost of healthcare in the urban areas versus the rural areas of Jamaica: In the city there are a lot more doctors, and a lot more people, doctors and medical professionals to assist you. In the rural areas you might have one hospital and one clinic that serves a span of may be a 35 mile radius or something. It's just this one clinic or community center that has one doctor serving over a 1,000 people and there's that's intense... but for the private doctors when you go, it's so expensive that you cannot afford to go there, and when you go to the health center or the hospitals, it takes so long for you to get to see the doctor, because of the high number of individuals waiting for doctors that by the time you get there some people are sick, falling down on the ground before they can get any medical attention.

Imani (Dominica) also refers to the high cost of medication and diabetes tools in Dominica: ...because a lot of times back home what would happen is that they don't have the access to the medication as we do up here (U.S.) or it's 
more expensive and they go without the medication or they have to find ways to make it stretch a bit more. To give an example, my aunt is a diabetic.... and the thing that you count your sugar on, she didn't have one up until a few years ago, my mother had to send her one [from the U.S.], and she got it and with the machine, there's a needle. She has to use it to prick herself and now the needle typically, when you get the supplies, every day you have to use a new needle, so for her knowing that's it a lot more expensive, she would use the same needle for about a week or so.

\section{Non-exercise culture}

The lack of exercise and physical activity was highlighted among the participants: ...definitely he (Maria's father) is not one who exercises and so, there's a possibility that had he included exercise in his schedule, and it was a regular part of his daily regimen, then there's a possibility that may have been able to avoid having diabetes... but, exercise or going to the gym is definitely not something that is, um, part of the St. Lucian individual's daily life. (Maria, St. Lucia)

"Well going to the gym in Barbados is rare... [Though] I mean that's becoming more common now" (Nola, Barbados).

\section{Cues to change health behaviors}

Maria (St. Lucia) explains that in addition to talking to her father, who resides in St. Lucia, on the importance of taking his diabetes medication and experiencing negative side effects from not taking his medication prompted him to take his medication as directed.

...after I one, spoke with him and further explained the importance of taking the medication, and also after experiencing the symptoms of dizziness, which were not pleasant, as a result served as an incentive to continue taking the medication on an everyday basis and not whenever he felt like it, because that's what he did.

Stephanie (Jamaica) explains that her grandmother's diagnosis of type II diabetes served as a prompt to change her lifestyle, to one that was more health-promoting: When she was doing her medical actually to come to the U.S.; she found out through that...When she came here (i.e. U.S.), she started treatment and talking to her doctor and stuff like that, she lost probably twenty pounds. She's being really cognizant of her weight since then.

\section{Preventative Measures}

To study participants, type II diabetes meant the measures put in place by their home country's respective governments to control the increasing prevalence of type II diabetes. Secondly, this theme also captures the changes that individuals have made to ensure that they are living healthier lives, despite the fact that they are diabetic. Lastly, this theme captures the responses from the participants that involve measures that could or should be put in place to ensure that incidence of type II diabetes decreases. Subthemes include: awareness, programs, research, and policy. Examples to support these themes are highlighted below.

\section{Awareness}

Ryan (St. Lucia) spoke about the heightened level of awareness and programs that have been put in place by the St. Lucian government as a response to the increasing prevalence of type II diabetes there: 
There's always some advertisement on the television about diabetes; information on your health and your weight, and diabetes, and your sugar. The schools, I think now also put that as part of their curriculum, food and nutrition and even lifestyle programs to, because you find a lot of young persons also have type I diabetes. So, yes; also at the health centers, it is mandatory now, just like you would take your blood pressure at a clinic or the hospital, it is also mandatory that they check your blood sugar on your finger.

\section{Programs}

Maria (St. Lucia) discusses how television could help to solve diabetes: I also think there should even be a government-funded show that probably comes on once a week... a 30 minute televised program that would actually incorporate food in some way and give persons examples of how food should be prepared and what their portion sizes should look like.

\section{Research}

Maria discusses how research should inform diabetes in the Caribbean: ... whether it is among educated St. Lucians who are able to do so, or whether it's in collaboration with professors in the U.S., but efforts should be made to clearly understand the condition of diabetes in St. Lucia, as well as other islands in terms of understanding the prevalence of diabetes, whether its among young children, adolescents, older adults, among men versus women, in order to devise interventions that would best tackle the problem.

\section{Policy}

Imani (Dominica) talks about how policy could decrease the number of fast food places in communities: Something like that could be done, where a developer, who decides to put a MacDonald's somewhere has to make sure that there aren't already two or three MacDonald's restaurants in that area. That can decrease the amount of fast food restaurants that we have in that area.

\section{Genetics}

To study participants, type II diabetes was not only about individual behaviors and environmental conditions. Genetics as a meaning of diabetes was evident throughout all interviews. That is, all participants thought about type II diabetes as being hereditary and "part of their families", as Imani (Dominica) noted:

I was diagnosed in the summer of 2011. Even before I was diagnosed, I am pretty sure that I had it, because I have a strong family history of it. My mother and father are also diabetic. I have at least two aunts who are diabetic and I have a brother who's diabetic. All my grandparents are, before they died were diabetic; as a matter of fact diabetes really contributed to their demise.

Also, Stephanie (Jamaica) perceived diabetes as being "something that travels in family lines":

Yes, because diabetes travels in a family line. Like we noticed, like I told you before my grandmother has it, my aunt and my grandmother are at risk. My other grandmother has it also. So, a lot of times you see it showing up along a family line, which is an indicator, though I am not entirely sure, but it could be an indicator of it being genetics. 


\section{Consequences}

Ultimately study participants made sense of type II diabetes in terms of its outcomes: its signs and symptoms (dizziness and sluggishness) to the surgery and amputation, a serious complication of diabetes and eventually death.

A lot of things that she [grandmother] could've done in the past: like her eyesight is getting really bad; her cooking has become an issue, cleaning and making sure that the house is done has become an issue, because she's not used to not having her full vision. So, few things like that and getting around to places has been very difficult...(Stephanie, Jamaica)

He [uncle] went to a regular check-up and he was gaining all this weight, feeling very tired all the time, and having weird symptoms...He was more sluggish...my aunt had it so bad that it messed with her vision, because she had to get surgery... (Mac, Jamaica)

Well, as of now he (father) has, I think, 5 siblings who are alive, and there were two who are dead, but of the two who are dead, there was one who had diabetes as well, and you know, toes were amputated, and he died from diabetes related causes. (Maria, St. Lucia)

\section{Seven years later (2019): Type II diabetes Impact on the family}

It's been 7 years since the initial interviews were conducted. Therefore, it is even more important to address this issue and understand how the interviewees continue to feel about the impact of diabetes on their families. Have their thoughts on the disease changed? How are their family members diagnosed with the disease affect their lives and that of their families?

Nola indicated that she didn't feel that there is more of a real impact of the disease on her family seven years later. Her grandmother's health is stable and hasn't deteriorated. In fact, no one else in her family has been diagnosed with type II diabetes.

Stephanie who discussed diabetes' effects on her grandmother's health, the progression of the disease and its impact on the family: Diabetic retinopathy has worsened where she's now legally blind in both eyes. She lives with family and cannot stay on her own. We, the family has to do everything for her, such as cook and transport every to different places. She is very dependent on others and I think this may have caused a bit of a depression.

Stephanie also indicated that although her disease progression has worsened, her grandmother still engages in notso-good habits. She states, "She is very stubborn in that she wants what she wants. Her mentality is that the pill is enough and that the other habits shouldn't have to change, such as eating and physical activity."

Imani's (Dominica) family tree is plagued by diabetes. She discussed how it controls what foods she eats and what her family eats, which is a sense of annoyance. She states:

... you do good a few days ... But for us, food has the power to take our lives. Diabetes controls us. It tells us what to eat and how frequently we should eat. It tells us when to go to the bathroom. It makes us uncomfortable. Diabetes affects our everything. We hate this disease, but this disease love us.

Mac (Jamaica), who discussed how his uncle's diagnosis of type II diabetes says that he continues to engage in healthy habits that has allowed him to take control of his illness. He says that the diagnosis "forced him to make better choices. My uncle looks fit and has to get new clothes, because he keeps losing weight." Mac also indicated that he has other family members who have a different approach to diabetes. Unlike his uncle who has a posi- 
tive approach to his diagnosis and who has control of it; there are other family members whose relationship with the disease is less than desirable. He states, "I do have family members, who are on medication, because they do not watch what they eat or workout. It's (diabetes) affected sight, movement, travel, etc. They act like they don't have it."

Maria (St. Lucia) has a strong family history of type II diabetes in her family as well. Seven years later she states that adherence (to diabetes medication) remains an issue among her uncles and her father. Despite the fact that there are numerous complication from the disease, she states that her father, "has occasional bouts of lightheadedness, nausea and faint spells." And more recently an uncle has a foot amputated, as a result of gangrene. She was asked about her family's response to their disease progression to which she responded, "they're supportive during periods of hospitalization - visiting, bringing food, but outside of encouraging them to take their medications, they simply employ a: 'everybody is grown and they will do as they please' mentality."

\section{Intersection of Adolescents, Families and Health}

The adults and families consistently spoke about the ways in which the entire family is either positively or negatively impacted by the health choices of the parents or adults. Community and familial health is visible in the following ways: adherence to prescribed medication, purchasing food, avoiding hospitalization, consistent physical activity, medical complications from diabetes, and a focus on prevention. As children become adolescents and adolescents become adults, it is imperative to intentionally integrate prevention and educational programs that support the entire family. Whether it is extended family such as cousins, aunts, uncles or siblings, children, parents or adults, developing programming that supports the entire family is critical. Managing a chronic condition for any family member is a difficult task. While focusing on preventing diabetes in all family members is important, being diagnosed and managing diabetes takes a toll on the entire family. Once a family member is diagnosed with Type II diabetes, changes occur at every level. From the foods eaten, groceries purchased, preparation of meals, medications needed, managing stress, and engaging in more exercise impacts all.

\section{Limitations}

A weakness of the study is the generalizability of the study. Due to the small sample size of the study participants, the findings from the interviews cannot be representative of all diabetic, Afro-Caribbean people in Dominica, St. Lucia, Jamaica and Barbados. More research is needed on the ground, in the Caribbean, to better understand how the increasing prevalence of type II diabetes affects the Afro-Caribbean family. It would be helpful for researchers to interview more individuals diagnosed with Type II diabetes, residing from each of these countries at different stages of diagnosis and treatment. Despite these weaknesses, the results from these interviews prove that type II diabetes is very much present and active in the Caribbean family and larger community. Further work on diabetes education and treatment in this population may be worthwhile to consider in future research. 


\section{Conclusion}

In this investigation, I found that while each participant's understanding on type II diabetes was unique, there were many shared beliefs and understanding that made this research interesting. For instance, all of the participants agreed that the lack of physical activity and unhealthy diets contributed to a rise in type II diabetes. While most of the participants alluded to importation of foreign foods in their countries as being detrimental to health; some of the participants explained that traditional foods were also the culprit. In their different ways, participants indicated that globalization and urbanization have played a central role to the increase in type II diabetes in the Caribbean, which has been discussed in the literature (Perel et al., 2006). Unfortunately, type II diabetes is very much present in the Afro-Caribbean home and in the Caribbean at large. Reasons for the high rate of this devastating disease were discussed as well as areas for improving it. Each participant painted a very important picture of how diabetes not only affects the individual with the disease, but the family unit as well. They are hurting and are negatively impacted by it and they want change.

Seven years later, the participants give an eye-opening view of the disease's progression not only on a certain family member, but on the entire family unit. The family unit is forever changed by this disease, such as is the case of caring for a family member who suffers poor health like in the case of Stephanie's and Maria's families dealing with diabetic retinopathy and amputations. Mac's uncle was an anomaly here. His uncle has the disease; however, he is in a general state of good health and that also has a direct impact on the family.

Exploring type II diabetes in the Caribbean is very important given that the WHO $(2005,2008 \mathrm{a})$ has predicted a rise in non-communicable disease globally, much of which will disproportionately affect much of the developing world. Although this study is not representative of all of Afro-Caribbean countries, it does provide a different perspective to studying diabetes in the Caribbean. Understanding how social determinants of health in certain regions impact communities differently can lead to strategic ways to decrease the prevalence of type II diabetes in the Caribbean.

\section{References}

Ali, M.K., Jaacks, L.M., Kowalski, A.J., Siegel, K.R., \& Ezzati, M. (2015). Noncommunicable diseases: Three decades of global data show a mixture of increases and decreases in mortality rates. Health Affairs, 34(9), 1444-1455. https://doi.org/10.1377/hlthaff.2015.0570

Barcelo, A., Aedo, C., Rajpathak, S. \& Robles, S. (2003). The cost of diabetes in Latin America and the Caribbean. Bulletin of the World Health Organization, 81, 19-27. Retrieved from https://www.ncbi.nlm.nih.gov/pmc/articles/PMC2572319/

Barclay, G. (2006). Health workforce migration and the Caribbean region. Retrieved from http://www.nationalacademies.org/hmd/ /media/Files/Activity\%20Files/Global/USandGlobalHealth/02Barclay.pdf 
Beaglehole, D., \& Yach, D. (2003). Globalisation and the prevention and control of non-communicable diseases: The neglected chronic diseases of adults. The Lancet, 362(9387), 903-908. https://doi.org/10.1016/S0140$\underline{6736(03) 14335-8}$

Bloom, D.E., Cafiero, E.T., Jané-Llopis, E., Abrahams-Gessel, S., Bloom, L.R., Fathima, S. ...Weinstein, C. (2011). The global economic burden of non-communicable diseases. Geneva: World Economic Forum [PDF file]. Retrieved from

http://www3.weforum.org/docs/WEF Harvard HE GlobalEconomicBurdenNonCommunicableDiseases 2011.pdf

Boyne, M.S. (2010). Diabetes in the Caribbean: Trouble in paradise. Insulin, 4(2), 94-105.

https://doi.org/10.1016/S1557-0843(09)80018-3

Bryan, G.C., Johnson, J.A., Dawes, L., \& Samuel, C. (2012). An assessment of the risk factors for type 2 diabetes among women in rural Jamaica. West Indian Medical Journal, 61(8), 808-812.

Brown, K., Avis, M. \& Hubbard, M. (2007). Health beliefs of African-Caribbean people with type 2 diabetes: A qualitative study. The British journal of general practice: the journal of the Royal College of General Practitioners, 57(539), 461-469. Retrieved from https://www.ncbi.nlm.nih.gov/pmc/articles/PMC2078187/pdf/bjpg57-461.pdf

Butler, C., Tull, E.S., Chamber, E.C., \& Jerome, T. (2002). Internalized racism, body fat distribution, and abnormal fasting glucose among African Caribbean women in Dominica, West Indies. Journal of National Medical Association, 94(3), 143-148. Retrieved from https://www.ncbi.nlm.nih.gov/pmc/articles/PMC2594102/

Cawich, S. O., Islam, S., Hariharan, S., Harnarayan, P., Budhooram, S., Ramsewak, S., \& Naraynsingh, V. (2014). The economic impact of hospitalization for diabetic foot infections in a Caribbean nation. The Permanente journal, 18(1), e101-e104. doi: 10.7812/TPP/13-096 Centers for Disease Control and Prevention. Social determinants of health: Know what affects health. Retrieved July 18, 2018, from https://www.cdc.gov/socialdeterminants/index.htm

Central Intelligence Agency. The world factbook. Retrieved August 29, 2018, from https://www.cia.gov/library/publications/the-world-factbook/docs/profileguide.html

Ferguson, T.S., Tulloch-Reid, M.K., Cunningham-Myrie, C.A., Davidson-Sadler, T., Copeland, S., Lewis-Fuller, E. \& Wilks, R. J. (2011). Chronic disease in the Caribbean: Strategies to respond to the public health challenge in the region. What can we learn from Jamaica's experience? West Indian Medical Journal, 60(4), 397-411.

Figueroa, J.P. (2001). Health trends in Jamaica. Significant progress and a vision for the 21 st century. West Indian Medical Journal, 50(4), 15-22. Retrieved from https://www.researchgate.net/publication/11536245 Health trends in Jamaica Significant progress and a vision for the 21 st century 
Giuffrida, A. (2010). Racial and ethnic disparities in Latin American and the Caribbean: A literature review. Diversity in Health and Care, 7, 115-128. Retrieved from http://diversityhealthcare.imedpub.com/racial-and-ethnicdisparities-in-latin-america-and-the-caribbean-a-literature-review.pdf

Guariguata, L., Whiting, D.R., Hambleton, I., Beagley, J., Linnenkamp, U., \& Shaw, J.E. (2014). Global estimates of diabetes prevalence for 2013 and projections for 2035. Diabetes Research and Clinical Practice, 103(2), $137-149$.

Gulliford, M.C. (1994). News from overseas: Health and health care in the English-speaking Car ibbean: A British public health physician's view of the Caribbean. Journal of Public Health Medicine, 16(3), 263269. https://doi.org/10.1093/oxfordjournals.pubmed.a042981

Hennis, A.J.M., Fraser, H.S., Jonnalagadda, R., Fuller, J., \& Chaturvedi, N. (2004). Explanations for the high risk of diabetes-related amputations in a Caribbean population of black African decent and potential for prevention. Diabetes Care, 27(11), 2636-2641. Retrieved from https://care.diabetesjournals.org/content/27/11/2636.long

Hospendales, C.J., Barcelo, A., Luciani, S., Legetic, B., Ordunez, P., \& Blanco, A. (2012). NCD prevention and control in Latin America and the Caribbean: A regional approach to policy and program development. Global Heart, 7(1), 73-81. Retrieved from https://www.sciencedirect.com/science/article/pii/S2211816012000154?via\%3Dihub

King, H., Aubert R. E., \& Herman, W.H. (1998). Global burden of diabetes, 1995-2025: Prevalence, numerical estimates, and projections. Diabetes Care, 21(9), 1414-1431. https://doi.org/10.2337/diacare.21.9.1414

Ley, F.H., Hamdy, O., Mohan, V., \& Hu, F.B. (2014). Prevention and management of type 2 diabetes: dietary components and nutritional strategies. Lancet, 383(9933), 1999-2007. Retrieved from

https://www.thelancet.com/journals/lancet/article/PIIS0140-6736(14)60613-9/fulltext

Lopez, A., Mathers, C., Ezzati, M., Jamison, D., \& Murray, C. (2006). Global and regional burden of disease and risk factors, 2001: Systematic analysis of population health data. Lancet, 367(9524), 1747-1757.

https://doi.org/10.1016/S0140-6736(06)68770-9

Mason, J. (2002). Qualitative Researching (Second ed.). London: Sage Publications Ltd.

Magnusson, R.S. (2010). Global health governance and the challenges of chronic, non-communicable diseases. Journal of Law, Medicine \& Ethics, 38(3), 490-507. https://doi.org/10.1111/j.1748-720X.2010.00508.x

Ministry of Health (Jamaica). Jamaica health \& lifestyle survey III (2016-2017): Preliminary key findings Jamaica 2018 [PDF file]. Retrieved from https://www.moh.gov.jm/wp-content/uploads/2018/09/Jamaica-Health-andLifestyle-Survey-III-2016-2017.pdf 
Ministry of Health (Barbados). Chief medical officer's report 2010-2012 [PDF file]. Retrieved from https://www.barbadosparliament.com/uploads/sittings/attachments/05530f55cc1d0cd01198dbc26b76209b.pdf

Miranda, J.J., Kinra, S., Casas, J.P., Smith,G.D., \& Ebrahim, S. (2008). Non-communicable diseases in low- and middle- income countries: context, determinants and health policy. Tropical Medicine and International Health, 13(10), 1225-1234. https://doi.org/10.1111/j.1365-3156.2008.02116.x

Mitchell-Fearon, K., Waldron, N., Laws, H., James, K., Holder-Nevins, D., Willie-Tyndale, D. \& Eldemire-Shearer, D. (2015). Non-communicable diseases in an older, aging population: A developing country perspective (Jamaica). Journal of Health Care for the Poor and Underserved, 26(2), 475-487. doi:10.1353/hpu.2015.0041

Noakes, H. (2010). Perceptions of black African and African-Caribbean people regarding insulin. Journal of Diabetes Nursing, 14(4), 148-156.

Pan American Health Organization (PAHO). (2007). Health in the Americas: Volume II-Countries [PDF file]. Washington, D.C.: PAHO. Retrieved from https://www.paho.org/hq/dmdocuments/2010/Health in the Americas Vol 2 Country Profiles 2007.pdf

Pan American Health Organization. (2012). Health in the Americas, 2012 Edition: Country Volume: Saint Lucia [PDF file]. Retrieved from https://www.paho.org/salud-en-las-americas-

2012/index.php?option=com docman\&view=download\&category slug=hia-2012-country-chapters-22\&alias=146saint-lucia-146\&Itemid=231\&lang=en

Pan American Health Organization. (2017). Health in the Americas+ 2017 edition. Summary: regional outlook and country profiles [PDF file]. Retrieved from https://www.paho.org/salud-en-las-americas-2017/wpcontent/uploads/2017/09/Print-Version-English.pdf

Pekua, P. (2002). Nutrition and global prevention on non-communicable diseases. Asia Pacific Journal of Clinical Nutrition, 11, S755-S758. https://doi.org/10.1046/j.1440-6047.11.s.5.x

Perel, P., Casas, J. P., Ortiz, Z., \& Miranda, J. J. (2006). Noncommunicable diseases and injuries in Latin American and the Caribbean: Time for action. PloS Medicine, 3(9), 1448-1451. https://doi.org/10.1371/journal.pmed.0030344

Popkin, B. M., Adair, L. S., \& Ng, S. W. (2012). Global nutrition transition and the pandemic of obesity in developing countries. Nutrition reviews, 70(1), 3-21. doi:10.1111/j.1753-4887.2011.00456.x

Punnett, J., Dick-Forde, E., \& Robinson, J. Effective management and culture: An analysis of three Englishspeaking Caribbean countries. Journal of Eastern Caribbean Studies, 31(2), 44-71. 
Reardon, T., Timmer, C.P., Barrett, C.B. \& Berdegue, J. (2003). The rise of supermarkets in Africa, Asia, and Latin America. American Journal of Agricultural Economics, 85, 1140-1146. http://dx.doi.org/10.1111/j.0092$\underline{5853.2003 .00520 . \mathrm{x}}$

Samuels, T.A. \& Fraser, H. (2010). Caribbean wellness day: Mobilizing a region for chronic non-communicable disease prevention and control. Pan American Journal of Public Health, 28(6), 472-479. Retrieved from https://www.scielosp.org/pdf/rpsp/2010.v28n6/472-479/en

Solomon, N.W. (2003). Diet and long-term health: An African diaspora perspective. Asia Pacific Journal of Clinical Nutrition, 12(3), 313-330. Retrieved from http://apjen.nhri.org.tw/server/APJCN/12/3/313.pdf

Taylor Jr., C.G., Krimholtz, M., Belgrave, K.C., Hambleton, I., George, N.C. \& Rayman, G. (2014). The extensive inpatient burden of diabetes and diabetes-related foot disease in Barbados. Clinical Medicine, 14(4), 367-370. doi: 10.7861/clinmedicine.14-4-367

Trouillot, M. (1992). The Caribbean Region: An open frontier in anthropological theory. Annual Review of Anthropology, 21, 19-42.

Wild, S., Roglic, G., Green, A., Sicree, R., \& King, H. (2004). Global prevalence of diabetes estimates for the year 2000 and projections for 2030. Diabetes Care, 27(5), 1047-1053.

Wilks, R., Bennett, F., Forrester, T., \& McFarlane-Anderson, N. (1998). Chronic disease: the new epidemic. West Indian Medical Journal, 47(4), 40-44. https://doi.org/10.2337/diacare.27.5.1047

World Health Organization. (2005). Preventing chronic disease: A vital assessment. WHO Global Report. Geneva, Switzerland. Retrieved from https://www.who.int/chp/chronic disease report/en/

World Health Organization. (2008a). World health statistics. Geneva, Switzerland. Retrieved from https://www.who.int/whosis/whostat/2008/en/

World Health Organization. (2008b). 2008-2013 action plan for the global strategy for the prevention and control of non-communicable diseases. Geneva, Switzerland. Retrieved from https://www.who.int/nmh/publications/ncd action plan en.pdf

World Health Organization. (2011, April 27). [Video].WHO: Unite in the fight against NCDs. Retrieved from http://www.youtube.com/user/who\#p/c/3FB3D1EAAD2DBE57/3/AvwX1m4LR4w

Yisahak, S.F., Beagley, J., Hambleton, I.R., \& Venkat Narayan, K.M. (2014). Diabetes in North America and the Caribbean: An update. Diabetes Research and Clinical Practice, 103(2014), 223-230. 
Zhang, Q., Wang, Y., \& Huang, E.S. (2009). Changes in racial/ethnic disparities in the prevalence of type 2 diabetes by obesity level among US adults. Ethnicity \& Health, 14(5), 439-457. https://doi.org/10.1080/13557850802699155 